\title{
Factors influencing the performance of supply chain management in Saudi SMEs
}

\author{
Nejah Ben Mabrouk ${ }^{a^{*}}$, Anis Omri ${ }^{\mathrm{b}}$ and Bilel Jarraya ${ }^{\mathrm{c}}$
}

${ }^{a}$ Department of Management Information Systems and Production Management, College of Business and Economics (CBE) - Qassim University, P.O.Box: 6640, Buraidah 51452, Saudi Arabia

${ }^{b}$ Department of Business Administration, College of Business and Economics, Qassim University, P.O.Box: 6640, Buraidah 51452, Saudi Arabia ${ }^{c}$ Department of Accounting, College of Business and Economics, Qassim University, P.O.Box: 6640, Buraidah 51452, Saudi Arabia

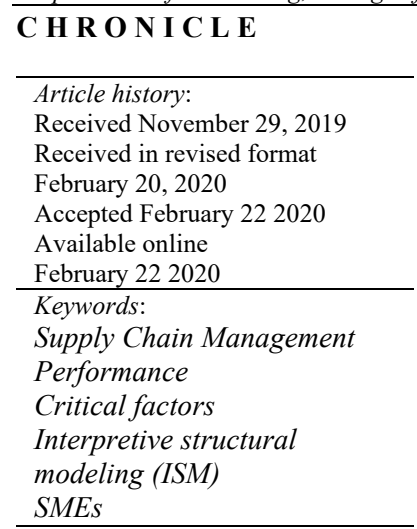

\begin{abstract}
A B S T R A C T
The aim of this paper is to provide a practical approach by using an interpretive structural modeling (ISM) approach to prioritize the most critical success factors that influence the supply chain output in small and medium enterprises (SMEs). The analysis of MICMAC was also considered for the identification of factors having a high power of influence. The findings show that the most significant factors with the highest driving power are associated with innovation and communication tools. Such findings can assist policy makers, administrators, and practitioners in formulating supply chain effectiveness strategies and policies.
\end{abstract}

\section{Introduction}

Supply Chain Management (SCM) efficiency is considered a critical field of operations management study. SCM comprises numerous interlinked resources and activities, beginning with the collection of raw materials from the sources needed to create products and services for customers (Cooper et al., 1997). SCM's main focus is on providing the right product to the consumers at the right cost, the right time, the right quality and the right amount. While, SCM's short-term strategic objective is to minimize cycle time and inventory and thus increase productivity, but the long-term objective is to increase profits through market share and customer service. The purpose of this study is to recognize, in a first step, the main factors that may contribute to the success of the supply chain from the existing literature, and in a second step, to construct a standardized model based on these different factors. In the context of Saudi SMEs, the motivators or critical factors that influence the supply chain output are established. In addition, we propose an ISM-based modeling framework to identify and summarize the relationship between factors that define an issue or problem (Sage, 1977). SCM performance variables or factors were identified through a detailed literature review; academic and industry expert views were also required. ISM approach was used to display the interrelationship between the factors and to classify their effect on SCM results.

\footnotetext{
* Corresponding author Tel.: +966507022176

E-mail address: mabrouknejah@gmail.com (N. Ben Mabrouk)

C 2020 by the authors; licensee Growing Science. doi: 10.5267 j.uscm.2020.2.006
} 
The present work therefore aims to deal with the following research questions: What are the driving factors or determinants of SCM performance? What is the interaction between the factors chosen? What determinants or variables have the high power of influence?

The present study aims to achieve the following research objectives by answering the above-mentioned research questions: First, to identify the critical factors that influence SCM. Then, to examine the relationship between identified critical factors. Finally, the study aims to evaluate the strength of the relationship between the factors influencing SCM performance and to identify significant factors. Our research adds to the current SCM success literature by offering a detailed model that consists of 14 factors defined from consultations with the field experts. The rest of the paper is organized as follow: A literature analysis on the success factors of SCM performance in the next section, followed by the solution methodology (section 3). Then, the interpretations and findings of the study are presented in section 4. Conclusions and further research directions are drawn in section 5.

\section{Literature review on the success factors of SCM performance}

To evaluate the performance of SCM, there are four factors need be considered: cost, quality, time, and flexibility. There are many different factors (variables) that affect SCM and in our research, these factors are classified in six-dimension: Environmental uncertainty (EU), Business Management (BM), Information Technology (IT), Manufacturing (M), Supply Chain relationships (SCR), Customer Satisfaction (CS), and SCM Performance (SCP).

\subsection{Environmental uncertainty (EU)}

(EU) refers to issues related to unpredicted change in environment variables and the degree of instability in technology, customer needs and tastes, supplier and competitor (Oke et al., 2012; Tohidi et al., 2012). To meet such unexpected changes, companies need to develop the ability to understand and cope with environmental changes (Wang et al., 2011a). According to Chen et al. (2004), It has been extensively approved that good supplier relationships can contribute positively and meaningfully to firm success. At the same time, supplier incorporation in product production processes is challenged in particular by procurement as a conduit between internal corporate clients and external suppliers (Florian et al., 2014). EU is regarded as a major factor in executing strategic supply plans. Several empirical studies show that some forms of uncertainties adversely affect the performance of the supply chain (Odkhishig \& Yoshiki, 2017, Chen \& Paulraj, 2004, Kim \& Chai, 2016, Shabnam et al., 2015). The definition of sub-factors in relation to environmental uncertainty is based on analysis of literature, there are three: Company environment (EU1), suppliers and competition (EU1) and uncertainty aspects from overseas (EU3).

\subsection{Business Management (BM)}

Based to literature, three different sub-factors are described in the Business management area: innovations, process strategy and marketing strategy. To achieve goals and objectives, BM consists on planning, organization and control of all the concerned actors and activities in company (Wang et al., 2011b). Companies use process techniques to boost their market and manufacturing efficiency (Kumar \& Mishra, 2017). Using the correct tools for the specific area of need is critical to obtain the perfections desired (Thomas et al., 2008). The marketing decisions included products, promotion, and distribution has a stronger contribution to the strategy field (Yang \& Gabrielsson, 2017). Innovation was described by Najafi-Tavani et al. (2018) as establishing a new service and method and the perception of the product on the market. There are two dimensions of product innovation success according to Hamid and Jabbari (2012), which are effectiveness and efficiency. Innovation in performance is representative of the level of innovation, but creative efficiency means the effort to succeed. There are three sub-

factors corresponding to business management: Process strategy (BM1), Marketing strategy (BM2) and innovation (BM3). 


\subsection{Information Technology (IT)}

In the SCM, communications and technology enable users to communicate with each other. In addition, the use of IT helps producers, vendors, distributors, consumers and retailers minimize paperwork, timeout and other unnecessary practices (Gunasekaran et al., 2017). The networking tools are primarily used to promote data transfer and to communicate between business units, mainly EDI, and facilitate the electronic transfer of funds. As Han et al. (2017) note, advances in information technology and their use in the supply chain make communication tools easier for users. Two sub-factors are related to the information technology: Communication (IT1) and tools planning tools (IT2).

\subsection{Customer Satisfaction (CS)}

The understanding of consumers is not always the same as that of the supplier. Customers want to obtain greater value on-time delivery, at low cost and at confirmed delivery date (Jesús et al., 2017). According to Xiao et al. (2010) and Wright (2013), at all times, retailers and manufacturers are looking for a post-sales process that allows them to reach the goal of customer satisfaction. Customer is the main and effective component in SCM. The important goal of the company to be successful in its field is to provide better services to customers in a very effective way (Tan, 2002; Wang et al., 2018).

\subsection{Supply chain relationship (SCR)}

To achieve the objectives of the company, the SCR depends on the synchronization and incorporation between suppliers and understands the needs of customers that bring great benefits to companies. SCM is directly interconnected to Relationship Management (Fynes et al., 2008; Artur et al., 2014), which includes customers and suppliers. Strategic coordination between customers and suppliers is also a key management practice in SCM (Carvalho et al., 2010; Flynn et al., 2010; Oosterhuis et al., 2013), resulting the exchange of information and experience. Relationship with suppliers (SCR1) and relationship with customers (SCR2) are considered in this factor (Sáenz et al., 2018).

\subsection{Manufacturing}

Added value can be defined as adding production or service measures to a product that the customer considers to increase its value. Customers usually would like to pay the exact cost they thought they should pay, and an added value is obtained when they get some additional features in the product. Dealing with added value is related to two important factors: flexibility and quality (Askariazad \& Wannous, 2009, Remigio et al. 2010). Flexibility is described as being able to interact and adapt quickly to market fluctuations. Market efficiency is measured by the extent to which a company can adapt and handle unexpected situations (Kurien \& Qureshi, 2015). The effect of flexibility on SCM performance is discussed by many studies. (e.g. Aprile et al., 2005, 2006; Shibin et al., 2016; Seebacher \& Winkler, 2015). Quality is the degree to which the goods meet the requirements of the customer, which is not only a reward for the customer but is also an important factor to sell the product. Poor quality means low level productivity, amplified costs and market share loss while the use of quality measures is used to measure the feasibility of the production system (Kumar \& Mishra, 2017). Three sub-factors are considered in manufacturing: Flexibility (M1), production system (M2) and quality (M3)

\section{Research Methodology}

\subsection{ISM approach}

ISM is an innovative approach, focused on business and academic expert assessments. ISM may be used to assess the contextual relationship between the different specifically defined factors of a problem or situation (Warfield, 1974). ISM is used in several applications in the SCM context: Risk in SCM (Mohamed, 2007; Faisal, 2006), vendor management (Anukul \& Deshmukh, 1994; Thakkar et al., 2010), reverse Supply chain (Govindan et al., 2012, Jayant \& Azhar, 2014; Lim et al., 2017), green supply chain (Jayant \& Azhar, 2014; Malviya \& Kant, 2017; Gardas et al., 2019a,b), sustainable supply chain (Kumar \& Rahman, 2017; Movahedipour et al., 2017; Rakesh et al., 2017; Bhaskar et al., 2019). Fig. 1 outlines the detailed steps of the research methodology. 


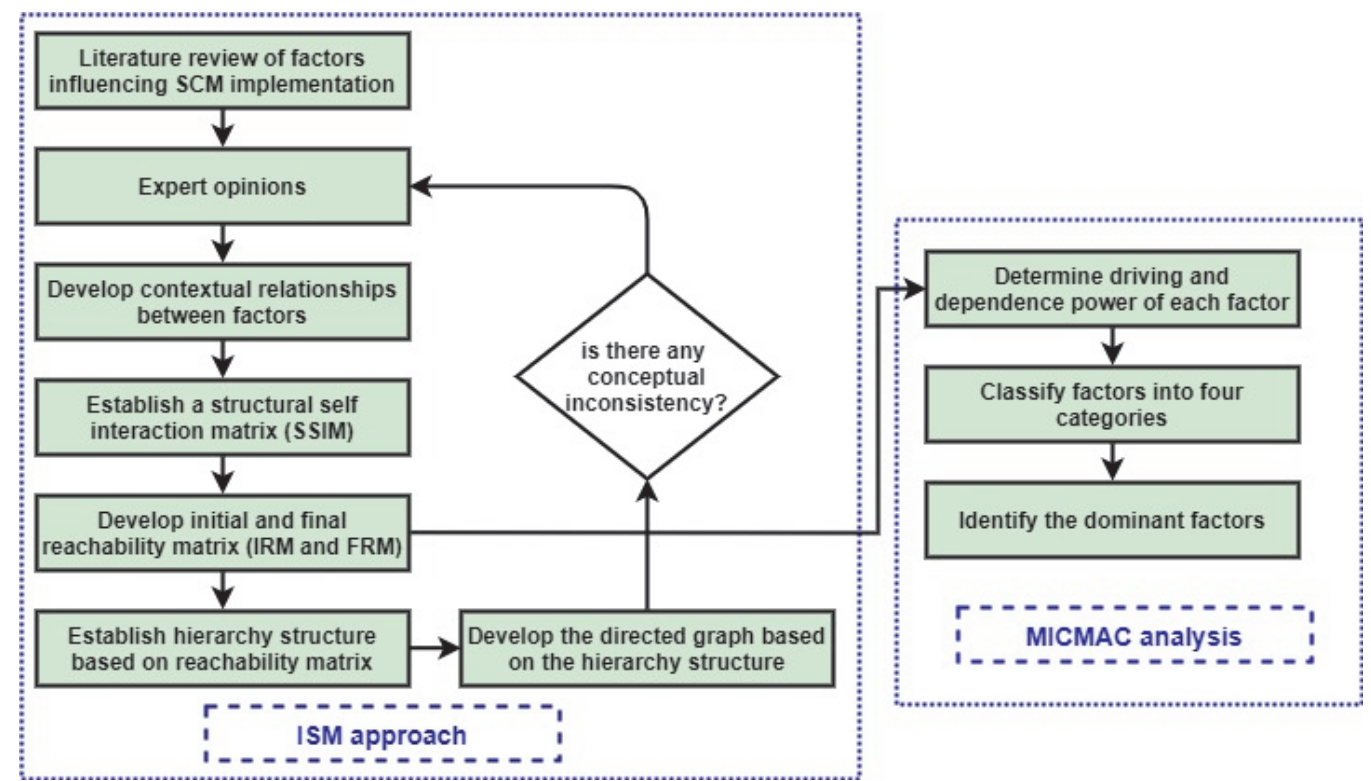

Fig. 1. Flow diagram of research methodology steps

\subsection{ISM Model Development}

\subsubsection{Identification of Critical Factors Influencing the SCM Performance}

Variables influencing the process are established through careful analysis of the literature and expert opinions on the case field. The ISM model suggests making use of the opinions of experts to define the conceptual relationship between selected variables. Participating in this study includes 50 experts or managers with extensive experience in SCM from various fields. Of these, 38 full replied questionnaires were completed (76\%). A pair-wise analysis of the 14 variables set out above (Table 1 ) by using of 5-pointer scale in which 5 is "Highly Influential", 4 represents "Influential", 3 represents "Neither influential Nor Important", 2 represents "Less Influential" and 1 represents "Not at all Influential".

Table 1

Critical Factors Influencing the SCM Performance

\begin{tabular}{|c|c|}
\hline Factors & References \\
\hline $\begin{array}{ll}\text { Environmental uncertainty (EU) } \\
\text { - } \\
\text { - } & \text { Suppliers and competition (EU2) } \\
\text { - } & \text { Uncertainty aspects from overseas (EU3) }\end{array}$ & $\begin{array}{l}\text { Wang et al. (2011), Oke et al. (2012), (Florian et al. 2014), } \\
\text { (Odkhishig \& Yoshiki, 2017), Chen and Paulraj (2004), Kim and } \\
\text { Chai (2016), Shabnam et al. (2015) }\end{array}$ \\
\hline $\begin{array}{l}\text { Business Management (BM) } \\
\begin{array}{l}\text { - } \\
\text { - }\end{array} \text { Mrocess strategy (BM1) } \\
\text { - } \quad \text { Innovation (BM3) }\end{array}$ & $\begin{array}{l}\text { Chang et al. (2018), Wang et al. (2011, (Thomas et al., 2008), } \\
\text { (Yang and Gabrielsson,2017), (Hamid and Jabbari, 2012), } \\
\text { (Najafi-Tavani et al., 2018) }\end{array}$ \\
\hline $\begin{array}{l}\text { Information technology (IT) } \\
\text { - Communication tools (IT1) } \\
\text { - } \quad \text { Planning tools (IT2) }\end{array}$ & $\begin{array}{l}\text { Gunasekaranet al. (2017), Dominguez et al. (2018), Singh et al. } \\
\text { (2012), Acar and Uzunlar (2014), }\end{array}$ \\
\hline 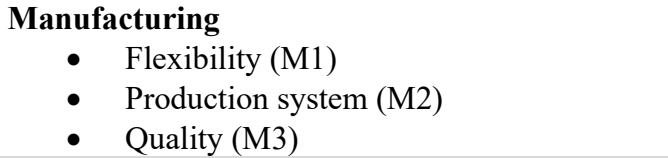 & $\begin{array}{l}\text { Askariazad and Wannous (2009), Remigio et al. (2010), Kurien } \\
\text { and Qureshi (2015), Aprile et al. (2005, 2006), Shibin et al. } \\
\text { (2016), Seebacher and Winkler (2015) }\end{array}$ \\
\hline $\begin{array}{l}\text { Supply chain relationship (SCR) } \\
\text { - Relationship with suppliers (SCR1) } \\
\text { - } \quad \text { Relationship with customers (SCR2) }\end{array}$ & Fynes et al., (2008), Su et al. (2008), Artur et al. (2014), \\
\hline - Customer satisfaction (CS) & $\begin{array}{l}\text { Jesús et al., (2017), Xiao et al., (2010), Wright (2013), Tan, } \\
\text { (2002), Wang et al. (2018), Oosterhuis et al. (2013) }\end{array}$ \\
\hline
\end{tabular}


The reliability of measures was validated using Cronbach's alpha coefficients on the responses from experts. Acceptable reliability level requires coefficients from 0.7 (Hair et al., 2011). To aggregate the answers of the experts used a threshold of 50\%. If more than $50 \%$ answered "Highly Influential" or "Influential", we considered factor $i$ contributes to factor $j$ or factor $j$ to $i$. Otherwise, $i$ and $j$ are considered unrelated.

\subsubsection{Development of SSIM}

The SSIM (Table 2) is constructed from the feed-back of the expert opinions. The relationships between two factors $i$ and $j$ is represented by the following notations:

$i / j-$ Where $i$ influences $j$ but $j$ has no effect on $i$;

$j / i$ - when $i$ does not lead to $j$ and $j$ does lead to $i$;

$i j$ - factors $i$ and $j$ will help to achieve each other; and

$N R$ - any relation of factors $i$ and $j$.

\subsubsection{Reachability Matrix (IRM)}

The IRM is produced from the SSIM as shown in Table 3, making use of the following rules: If the (i, $\mathrm{j})$ cell is $i / j$, replace then by 1 and $(\mathrm{j}, \mathrm{i})$ entry by 0 . If the $(\mathrm{i}, \mathrm{j})$ cell is $j / i$, replace then by 0 and $(\mathrm{j}, \mathrm{i})$ entry by 1 . If the $(\mathrm{i}, \mathrm{j})$ entry is $i j$, replace then by 1 and $(\mathrm{j}, \mathrm{i})$ by 1 . If the $(\mathrm{i}, \mathrm{j})$ entry is $N R$, replace then by 0 and $(\mathrm{j}, \mathrm{i})$ by 0 . The FRM (Table 4 ) is derived from the IRM, taking into account transitivity rules. The transitivity principle is based on the following: if variable $x$ is related to $y$ and $y$ is linked to $z$, then $x$ is necessarily related to $z$. In fact, any transitive connections between different variables should be explored (Sushil, 2017).

\section{Table 2}

SSIM Matrix of the Critical Factors of SCM Performance

\begin{tabular}{|c|c|c|c|c|c|c|c|c|c|c|c|c|c|c|c|c|}
\hline No. & Factors & 1 & 2 & 3 & 4 & 5 & 6 & 7 & 8 & 9 & 10 & 11 & 12 & 13 & 14 & 15 \\
\hline 1 & (EU1) & $i j$ & $i / j$ & $i j$ & $i / j$ & $i / j$ & $N R$ & $\overline{i / j}$ & $i / j$ & $i / j$ & $N R$ & $N R$ & $i / j$ & $i / j$ & $N R$ & $i / j$ \\
\hline 2 & (EU2) & & $i j$ & $i j$ & $i / j$ & $i / j$ & $N R$ & $N R$ & $N R$ & $i / j$ & $N R$ & $N R$ & $i / j$ & $i / j$ & $N R$ & $i / j$ \\
\hline 3 & (EU3) & & & $i j$ & $i / j$ & $i / j$ & $N R$ & $j / i$ & $N R$ & $i / j$ & $N R$ & $N R$ & $i / j$ & $i / j$ & $N R$ & $i / j$ \\
\hline 4 & (BM1) & & & & $i j$ & $i / j$ & $j / i$ & $j / i$ & $i / j$ & $i / j$ & $i / j$ & $N R$ & $N R$ & $N R$ & $N R$ & $i / j$ \\
\hline 5 & (BM2) & & & & & $i j$ & $j / i$ & $j / i$ & $N R$ & $j / i$ & $N R$ & $j / i$ & $j / i$ & $j / i$ & $i j$ & $i / j$ \\
\hline 6 & (BM3) & & & & & & $i j$ & $i / j$ & $i / j$ & $i / j$ & $i / j$ & $i / j$ & $N R$ & $N R$ & $i / j$ & $i / j$ \\
\hline 7 & (IT1) & & & & & & & $i j$ & $i j$ & $i / j$ & $N R$ & $i / j$ & $i / j$ & $i / j$ & $N R$ & $i / j$ \\
\hline 8 & (IT2) & & & & & & & & $i j$ & $i / j$ & $i / j$ & $i / j$ & $N R$ & $N R$ & $N R$ & $i / j$ \\
\hline 9 & (M1) & & & & & & & & & $i j$ & $i j$ & $i / j$ & $N R$ & $i / j$ & $i / j$ & $i / j$ \\
\hline 10 & (M2) & & & & & & & & & & $i j$ & $i / j$ & $N R$ & $N R$ & $i / j$ & $i / j$ \\
\hline 11 & (M3) & & & & & & & & & & & $i j$ & $i / j$ & $i / j$ & $i / j$ & $i / j$ \\
\hline 12 & (SCR1) & & & & & & & & & & & & $i j$ & $i j$ & $N R$ & $i / j$ \\
\hline 13 & (SCR2) & & & & & & & & & & & & & $i j$ & $i j$ & $i / j$ \\
\hline 14 & (CS) & & & & & & & & & & & & & & $i j$ & $i / j$ \\
\hline 15 & SCMP & & & & & & & & & & & & & & & $i j$ \\
\hline
\end{tabular}

\section{Table 3}

Initial Reachability Matrix (IRM)

\begin{tabular}{|c|c|c|c|c|c|c|c|c|c|c|c|c|c|c|c|}
\hline No. & 1 & 2 & 3 & 4 & 5 & 6 & 7 & 8 & 9 & 10 & 11 & 12 & 13 & 14 & 15 \\
\hline 1 & 1 & 1 & 1 & 1 & 1 & 0 & 1 & 1 & 1 & 0 & 0 & 1 & 1 & 0 & 1 \\
\hline 2 & 0 & 1 & 1 & 1 & 1 & 0 & 0 & 0 & 1 & 0 & 0 & 1 & 1 & 0 & 1 \\
\hline 3 & 1 & 1 & 1 & 1 & 1 & 0 & 0 & 0 & 1 & 0 & 0 & 1 & 1 & 0 & 1 \\
\hline 4 & 0 & 0 & 0 & 1 & 1 & 0 & 0 & 1 & 1 & 1 & 0 & 0 & 0 & 0 & 1 \\
\hline 5 & 0 & 0 & 0 & 0 & 1 & 0 & 0 & 0 & 0 & 0 & 0 & 0 & 0 & 1 & 1 \\
\hline 6 & 0 & 0 & 0 & 1 & 1 & 1 & 1 & 1 & 1 & 1 & 1 & 0 & 0 & 1 & 1 \\
\hline 7 & 0 & 0 & 1 & 1 & 1 & 0 & 1 & 1 & 1 & 0 & 1 & 1 & 1 & 0 & 1 \\
\hline 8 & 0 & 0 & 0 & 0 & 0 & 0 & 1 & 1 & 1 & 1 & 1 & 0 & 0 & 0 & 1 \\
\hline 9 & 0 & 0 & 0 & 0 & 1 & 0 & 0 & 0 & 1 & 1 & 1 & 0 & 1 & 1 & 1 \\
\hline 10 & 0 & 0 & 0 & 0 & 0 & 0 & 0 & 0 & 1 & 1 & 1 & 0 & 0 & 1 & 1 \\
\hline 11 & 0 & 0 & 0 & 0 & 1 & 0 & 0 & 0 & 0 & 0 & 1 & 1 & 1 & 1 & 1 \\
\hline 12 & 0 & 0 & 0 & 0 & 1 & 0 & 0 & 0 & 0 & 0 & 0 & 1 & 1 & 0 & 1 \\
\hline 13 & 0 & 0 & 0 & 0 & 1 & 0 & 0 & 0 & 0 & 0 & 0 & 1 & 1 & 1 & 1 \\
\hline 14 & 0 & 0 & 0 & 0 & 1 & 0 & 0 & 0 & 0 & 0 & 0 & 0 & 1 & 1 & 1 \\
\hline 15 & 0 & 0 & 0 & 0 & 0 & 0 & 0 & 0 & 0 & 0 & 0 & 0 & 0 & 0 & 1 \\
\hline
\end{tabular}


Table 4

Final reachability matrix (FRM)

\begin{tabular}{lllllllllllllllll}
\hline No. & $\mathbf{1}$ & $\mathbf{2}$ & $\mathbf{3}$ & $\mathbf{4}$ & $\mathbf{5}$ & $\mathbf{6}$ & $\mathbf{7}$ & $\mathbf{8}$ & $\mathbf{9}$ & $\mathbf{1 0}$ & $\mathbf{1 1}$ & $\mathbf{1 2}$ & $\mathbf{1 3}$ & $\mathbf{1 4}$ & $\mathbf{1 5}$ & Driving Power (DRP) \\
\hline $\mathbf{1}$ & 1 & 1 & 1 & 1 & 1 & 0 & 1 & 1 & 1 & $1^{*}$ & $1^{*}$ & 1 & 1 & $1^{*}$ & 1 & 14 \\
$\mathbf{2}$ & $1^{*}$ & 1 & 1 & 1 & 1 & 0 & 0 & $1^{*}$ & 1 & $1^{*}$ & $1^{*}$ & 1 & 1 & $1^{*}$ & 1 & 13 \\
$\mathbf{3}$ & 1 & 1 & 1 & 1 & 1 & 0 & $1^{*}$ & $1^{*}$ & 1 & $1^{*}$ & $1^{*}$ & 1 & 1 & $1^{*}$ & 1 & 14 \\
$\mathbf{4}$ & 0 & 0 & 0 & 1 & 1 & 0 & $1^{*}$ & 1 & 1 & 1 & $1^{*}$ & 0 & $1^{*}$ & $1^{*}$ & 1 & 10 \\
$\mathbf{5}$ & 0 & 0 & 0 & 0 & 1 & 0 & 0 & 0 & 0 & 0 & 0 & 0 & $1^{*}$ & 1 & 1 & 4 \\
$\mathbf{6}$ & 0 & 0 & $1^{*}$ & 1 & 1 & 1 & 1 & 1 & 1 & 1 & 1 & $1^{*}$ & $1^{*}$ & 1 & 1 & 13 \\
$\mathbf{7}$ & $1^{*}$ & $1^{*}$ & 1 & 1 & 1 & 0 & 1 & 1 & 1 & $1^{*}$ & 1 & 1 & 1 & $1^{*}$ & 1 & 14 \\
$\mathbf{8}$ & 0 & 0 & $1^{*}$ & $1^{*}$ & $1^{*}$ & 0 & 1 & 1 & 1 & 1 & 1 & $1^{*}$ & $1^{*}$ & $1^{*}$ & 1 & 12 \\
$\mathbf{9}$ & 0 & 0 & 0 & 0 & 1 & 0 & 0 & 0 & 1 & 1 & 1 & $1^{*}$ & 1 & 1 & 1 & 8 \\
$\mathbf{1 0}$ & 0 & 0 & 0 & 0 & $1^{*}$ & 0 & 0 & 0 & 1 & 1 & 1 & $1^{*}$ & $1^{*}$ & 1 & 1 & 8 \\
$\mathbf{1 1}$ & 0 & 0 & 0 & 0 & 1 & 0 & 0 & 0 & 0 & 0 & 1 & 1 & 1 & 1 & 1 & 6 \\
$\mathbf{1 2}$ & 0 & 0 & 0 & 0 & 1 & 0 & 0 & 0 & 0 & 0 & 0 & 1 & 1 & $1^{*}$ & 1 & 5 \\
$\mathbf{1 3}$ & 0 & 0 & 0 & 0 & 1 & 0 & 0 & 0 & 0 & 0 & 0 & 1 & 1 & 1 & 1 & 5 \\
$\mathbf{1 4}$ & 0 & 0 & 0 & 0 & 1 & 0 & 0 & 0 & 0 & 0 & 0 & $1^{*}$ & 1 & 1 & 1 & 5 \\
$\mathbf{1 5}$ & 0 & 0 & 0 & 0 & 0 & 0 & 0 & 0 & 0 & 0 & 0 & 0 & 0 & 0 & 1 & 1 \\
\hline $\begin{array}{l}\text { Dependence } \\
\text { Power (DNP) }\end{array}$ & 2 & 2 & 4 & 5 & 12 & 1 & 5 & 5 & 7 & 7 & 8 & 10 & 12 & 12 & 13 & $105 / 105$ \\
\hline & & & & & & & & & & & & & & & & \\
\hline
\end{tabular}

\subsubsection{Level Partitions}

The reachability and antecedent sets are derived from the FRM (Warfield, 1974). The reachability set is known as a set of all the variables which affect the other variables. The antecedent set represents a set of all those variables affected by other variables. The intersection set includes the common elements between antecedent and reachability set. The variable with the same reachability and the intersection sets is graded in the top-level in the ISM hierarchy (Table 5). All other factors drive this variable and it does not influence elements. This variable was not considered for next iteration. The element represented in the top level are removed and this procedure is iteratively repeated until levels of all factors are determined (Table 6).

Table 5

Level partitions (Iteration I)

\begin{tabular}{|c|c|c|c|c|}
\hline Factor & Reachability set & Antecedent set & Intersection set & level \\
\hline 1 & $1,2,3,4,5,7,8,9,10,11,12,13,14,15$ & $1,2,3,7$ & $1,2,3,7$ & \\
\hline 2 & $1,2,3,4,5,8,9,10,11,12,13,14,15$ & $1,2,3,7$ & $1,2,3$ & \\
\hline 3 & $1,2,3,4,5,7,8,9,10,11,12,13,14,15$ & $1,2,3,6,7,8$ & $1,2,3,7,8$ & \\
\hline 4 & $4,5,7,8,9,10,11,13,14,15$ & $1,2,3,4,6,7,8$ & $4,7,8$ & \\
\hline 5 & $5,13,14,15$ & $1,2,3,4,5,6,7,8,9,10,11,12,13,14$ & $5,13,14$ & \\
\hline 6 & $3,4,5,6,7,8,9,10,11,12,13,14,15$ & 6 & 6 & \\
\hline 7 & $1,2,3,4,5,7,8,9,10,11,12,13,14,15$ & $1,3,4,6,7,8$ & $1,3,4,7,8$ & \\
\hline 8 & $3,4,5,7,8,9,10,11,12,13,14,15$ & $1,2,3,4,6,7,8$ & $3,4,7,8$ & \\
\hline 9 & $5,9,10,11,12,13,14,15$ & $1,2,3,4,6,7,8,9,10$ & 9,10 & \\
\hline 10 & $5,9,10,11,12,13,14,15$ & $1,2,3,4,6,7,8,9,10$ & 9,10 & \\
\hline 11 & $5,11,12,13,14,15$ & $1,2,3,4,6,7,8,9,10,11$ & 11 & \\
\hline 12 & $5,12,13,14,15$ & $1,2,3,6,7,8,9,10,11,12,13,14$ & $12,13,14$ & \\
\hline 13 & $5,12,13,14,15$ & $1,2,3,4,5,6,7,8,9,10,11,12,13,14$ & $5,12,13,14$ & \\
\hline 14 & $5,12,13,14,15$ & $1,2,3,4,5,6,7,8,9,10,11,12,13,14$ & $5,12,13,14$ & \\
\hline 15 & 15 & $1,2,3,4,5,6,7,8,9,10,11,12,13,14,15$ & 15 & L1 \\
\hline
\end{tabular}

Table 6

Level Partitions (Iteration I to IX)

\begin{tabular}{|c|c|c|c|c|}
\hline Factor & Reachability set & Antecedent set & Intersection set & level \\
\hline 5 & $5,13,14$ & $1,2,3,4,5,6,7,8,9,10,11,12,13,14$ & $5,13,14$ & L2 \\
\hline 13 & $5,12,13,14$ & $1,2,3,4,5,6,7,8,9,10,11,12,13,14$ & $5,12,13,14$ & L2 \\
\hline 14 & $5,12,13,14$ & $1,2,3,4,5,6,7,8,9,10,11,12,13,14$ & $5,12,13,14$ & L2 \\
\hline 12 & 12 & $1,2,3,6,7,8,9,10,11,12$ & 12 & $\mathbf{L 3}$ \\
\hline 11 & 11 & $1,2,3,4,6,7,8,9,10,11$ & 11 & L4 \\
\hline 9 & 9,10 & $1,2,3,4,6,7,8,9,10$ & 9,10 & L5 \\
\hline 10 & 9,10 & $1,2,3,4,6,7,8,9,10$ & 9,10 & L5 \\
\hline 4 & $4,7,8$ & $1,2,3,4,6,7,8$ & $4,7,8$ & L6 \\
\hline 8 & $3,4,7,8$ & $1,2,3,4,6,7,8$ & $3,4,7,8$ & L6 \\
\hline 1 & $1,2,3,7$ & $1,2,3,7$ & $1,2,3,7$ & L7 \\
\hline 2 & $1,2,3$ & $1,2,3,7$ & $1,2,3$ & L7 \\
\hline 3 & $1,2,3,7$ & $1,2,3,6,7$ & $1,2,3,7$ & L7 \\
\hline 7 & 7 & 6,7 & 7 & L8 \\
\hline 6 & 6 & 6 & 6 & L9 \\
\hline
\end{tabular}




\subsubsection{Development of ISM Model}

The structural model of critical factors affecting SCM performance is created from level partition presented in Tables 5 and 6 . The resulted graph is converted into the ISM model after removing the transitivity, as shown in Fig. 2.

It is perceived from the ISM model that innovation factor (BM3) is a very significant variable of SCM performance for SMEs as it comes at the base of the ISM hierarchy.

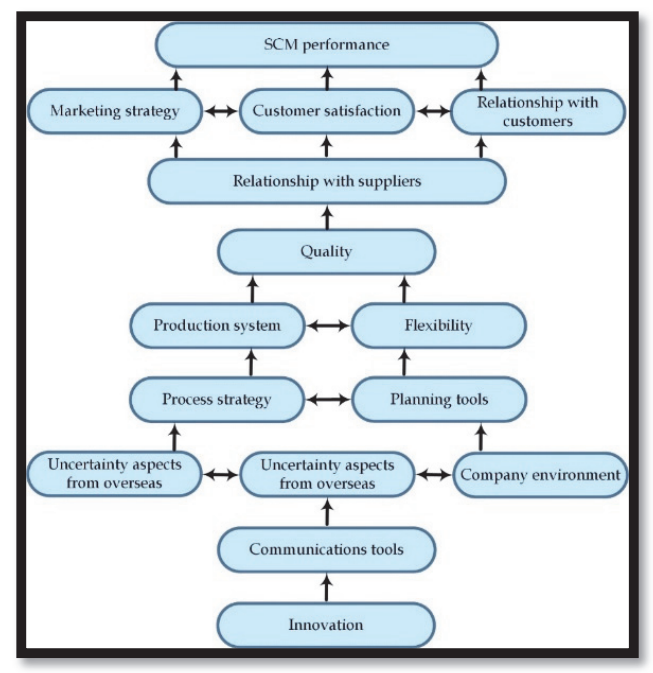

Fig. 3. ISM- Based Model for the Critical Factors of SCM Performance

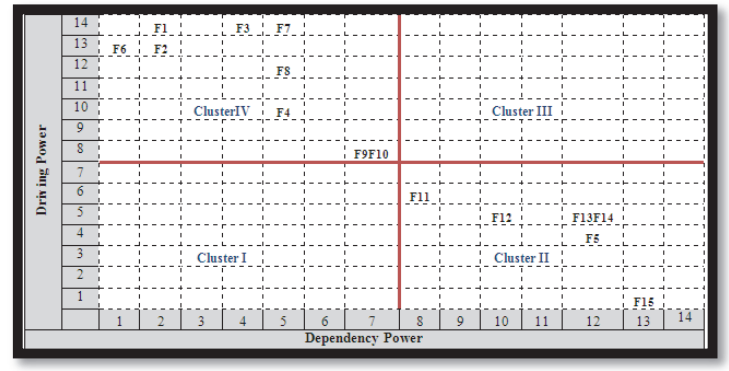

Fig. 3. Dependency Power- Driving Power matrix

\subsubsection{Classification of factors affecting SCM performance}

The goal of factor classification is to evaluate the DRP and DNP of factors (Mandal \& Deshmukh, 1994). Giving this classification, there are 4 categories: First cluster (autonomous) is formed by the variables that have a weak DRP and DNP. Such variables are detached from the process. There are no autonomous variables in this study. The second category (dependent) includes variables with weak DRP and strong DNP. For the SCM performance, this category contains 5 factors: BM2, M3, SCR1, SCR2, CS and SCMP. The third category (linkage) involves variables having strong DRP and DNP. In our study, there is no factors in the category of linkage factors. The fourth cluster (independent) is formed by the variables characterized by a strong DRP and weak DNP. In our study, this cluster category 9 factors (EU1, EU2, EU3, BM1, BM3, IT1, IT2, M1 and M2).

\section{Discussion and Findings}

The main purpose of this research is to analyze the relation between the various factors influencing SCM implementation and to create a hierarchy of SCM variables that would allow the decision makers to consider these factors. However, an ISM-based model was built on SCM performance factors. Driving and dependency diagram (Fig. 3) gives also several interesting observations:

- The lack of autonomous factors in this research indicates that all of the factors involved play an important role in impeding the implementation of SCM. Therefore, the decision makers should pay more attention to all the influencing factors for the successful implementation of SCM.

- Factors such as "relationship with suppliers", "relationship with customers", "marketing", and "quality" have low driving forces but a heavy dependence on other factors. Such variables are therefore put at the top of the ISM hierarchy (Fig. 2). Certain causes are an adverse result for administrators and practitioners of the SCM. Managers should therefore be particularly careful to deal with those factors. 
- The independent factors such as "production system", "flexibility", "communication tools", "planning tools", "process strategy", "environment uncertainty" and "innovation" are at the bottom of ISM hierarchy. Those factors have powerful DRP and weak DNP. Decision-makers should therefore place high importance in addressing these factors that can affect other factors. Therefore, these variables could be viewed as the "major factors" to the SCM performance.

- The outcome of the ISM model's hierarchy of variables offers decision makers, administrators or practitioners a strategic direction in formulating the effective strategies and policies for SCM implementation. The levels obtained through the ISM methodology will also help managers prioritize their SCM strategies. In our analysis, as well as in (Lii \& Kuo, 2016), F6: "Innovation" is without doubt the most important aspect in the SCM implementation, it appears at the bottom of the hierarchy. F7: "Communication tools" is also very relevant in our research. A key finding of this research is that "Innovation" and "Communication tools" are significant factors. It is reported from the ISM model that "Innovation" and "Communication Tools" are at the upper level of the hierarchy which implies higher driving power for these factors. Hence, managers should take special care to handle these factors.

\section{Conclusions and Further Research}

An increasing number of businesses have begun to realize the value of enhancing SCM. There are different factors affecting the SCM implementation. In this study, a detailed model comprising 14 factors defined from extensive literature review and expert consultations was developed. By using the ISM approach, the identified factors of SCM implementation are classified into eight levels. The ISM approach has shown that all the factors considered are very important in the implementation of SCM. Eventually, this work contributes immensely to the current Knowledge Body of the management and theoretical Supply Chain: (i) Through presenting an exhaustive and clear list of supply chain success factors; (ii) By using a theoretical framework to derive the simple interlinks and hierarchy of those factors; (iii) Classification of the variables according to their driving and dependency power; and (iv) Formulating an answer to multiple research gaps in the supply chain field. To improve accuracy and reliability of the model, it is imperative to use others approaches such as: Multi-criteria decisionmaking and structural equation modeling approach.

\section{Acknowledgments}

This study has been conducted by a fund granted from the Deanship of Scientific Research in Qassim University, Saudi Arabia.

\section{References}

Acar, A. Z., \& Uzunlar, M. B. (2014). The effects of process development and information technology on timebased supply chain performance. Procedia-Social and Behavioral Sciences, 150, 744-753.

Anukul, M., \& Deshmukh, S.G. (1994). Vendor selection Using Interpretive Structural Modelling (ISM). International Journal of Operations and Production Management, 14(6), 52-59.

Aprile, D., Garavelli A. C., \& Giannoccaro, I. (2005). Operations Planning and Flexibility in a Supply Chain. Production Planning \& Control, 16(1), 21-31.

Aprile, D., Garavelli, A. C., \& Giannoccaro I. (2006). A Cost Analysis of Supply Chain Flexibility Configurations. International Journal of Services Technology and Management, 7(5/6), 535-551.

Artur, L., Brito, L., Pereira, E., Brito, Z., \& Hashiba, L. H. (2014). What type of cooperation with suppliers and customers leads to superior performance? Journal of Business Research, 67(5), 952-959.

Askariazad, M., \& Wanous, M. (2009). A proposed value model for prioritizing supply chain performance measures. International Journal of Business Performance and Supply Chain Modelling, 1, 115-128.

Carvalho, H., Azevedo, S. G., \& Cruz-Machado, V. (2010). Supply chain performance management: lean and green paradigms. International Journal of Business Performance and Supply Chain Modelling, 2(3-4), 304-333.

Chang, H. H., Wong, K. H., \& Chiu, W. S. (2019). The effects of business systems leveraging on supply chain performance: Process innovation and uncertainty as moderators. Information \& Management, 56(6), 103140. 
Chen, I. J., \& Paulraj, A. (2004). Towards a theory of supply chain management: The constructs and measurements. Journal of Operations Management, 22(2), 119-150.

Chen, I.J, Paulraj, A., \& Lado, A.A. (2004). Strategic purchasing, supply management and firm performance. Journal of Operations Management, 22, 505-523.

Cooper, M. C., Lambert, D. M. \& Pagh, J. D. (1997). Supply chain management: more than a new name for logistics. The International Journal of Logistics Management, 8(1), 1-13.

Dominguez, R., Cannella, S., Barbosa-Póvoa, A.P., \& Framinan, J.M. (2018). OVAP: A strategy to implement partial information sharing among supply chain retailers. Transportation Research Part E: Logistics and Transportation Review, 110, 122-136.

Faisal, M.N., Banwet, D.K., \& Shankar, R. (2006). Supply Chain Risk Mitigation: Modelling the Enablers. Business Process Management Journal, 12(4), 535-552.

Flynn, B. B., Huo, B., \& Zhao, X. (2010). The impact of supply chain integration on performance: A contingency and configuration approach. Journal of Operations Management, 28(1), 58-71.

Fynes, B., De Búrca, S., \& Mangan, J. (2008). The effect of relationship characteristics on relationship quality and performance. International Journal of Production Economics, 111(1), 56-69.

Gardas, B.B, Raut, R.D, \& Narkhede, B. (2019a). Determinants of sustainable supply chain management: A case study from the oil and gas supply chain. Sustainable Production and Consumption, 17, 241-253.

Gardas, B., Raut, R., Jagtap, A. H., \& Narkhede, B. (2019b). Exploring the key performance indicators of green supply chain management in agro-industry. Journal of Modelling in Management, 14(1), 260-283.

Govindan, K., Palaniappan, M., Zhu, Q., \& Kannan, D. (2012). Analysis of third-party reverse logistics provider using interpretive structural modeling. International Journal of Production Economics, 140(1), 204-211.

Gunasekaran, A., Subramanian, N., \& Papadopoulos, T. (2017). Information technology for competitive advantage within logistics and supply chains: A review. Transportation Research Part E: Logistics and Transportation Review, 99, 14-33.

Hair, J. F., Ringle, C. M., \& Sarstedt, M. (2011). PLS-SEM: indeed a silver bullet. Journal of Marketing Theory and Practice, 19, 129-151.

Jayant, A., \& Azhar, M. (2014). Analysis of the Barriers for Implementing Green Supply Chain Management (GSCM) Practices: An Interpretive Structural Modeling (ISM) Approach. Procedia Engineering, 97, 2157-2166.

Kim, M., \& Chai, S. (2016). Assessing the impact of business uncertainty on supply chain integration. The International Journal of Logistics Management, 27(2), 463-485.

Kurien, G.P., \& Qureshi, M.N. (2015). Analysis and measurement of supply chain flexibility. International Journal of Logistics Systems and Management, 21(1), 70-91.

Kumar, D., \& Rahman, Z. (2017). Analyzing enablers of sustainable supply chain: ISM and fuzzy AHP approach. Journal of Modelling in Management, 12(3), 498-524.

Lii, P., \& Kuo, F.I. (2016). Innovation-oriented supply chain integration for combined competitiveness and firm performance. International Journal of Production Economics, 174, 142-155.

Lim, M.K., Tseng, M.L, Tan, K.H, \& Bui, T.D. (2017). Knowledge management in sustainable supply chain management: Improving performance through an interpretive structural modelling approach. Journal of Cleaner Production, 162, 806-816.

Malviya, R.K., \& Kant, R. (2017). Modeling the enablers of green supply chain management: An integrated ISM - fuzzy MICMAC approach. Benchmarking: An International Journal, 24(2), 536-568.

Movahedipour, M., Zeng, J., Yang, M., \& Wu, X. (2017). An ISM approach for the barrier analysis in implementing sustainable supply chain management: An empirical study. Management Decision, 55(8), 1824-1850.

Odkhishig, G., \& Yoshiki, M. (2017). Impact of environmental uncertainty on supply chain integration. The Journal of Operations Management and Strategy, 7, 37-56.

Oke, A., Walumbwa, F. O., \& Myers, A. (2012). Innovation Strategy, Human Resource Policy, and Firms' Revenue Growth: The Roles of Environmental Uncertainty and Innovation Performance. Decision Sciences, 43(2), 273-302.

Oosterhuis, M., Molleman, E., \& van der Vaart, T. (2013). Differences in buyers' and suppliers' perceptions of supply chain attributes. International Journal of Production Economics, 142(1), 158-171. 
Raut, R. D., Narkhede, B., \& Gardas, B. B. (2019). To identify the critical success factors of sustainable supply chain management practices in the context of oil and gas industries: ISM approach. Renewable and Sustainable Energy Reviews, 68(1), 2017, 33-47.

Rezapour, S., Allen, J.K., \& Mistree, F. (2015). Uncertainty propagation in a supply chain or supply network. Transportation Research Part E: Logistics and Transportation Review, 73, 185-206.

Sage, A. (1977). Interpretive Structural Modelling: Methodology for Large scale Systems (pp. 91-164). New York: McGraw-Hill.

Shibin, K. T., Gunasekaran, A., Papadopoulos, T., Dubey, R., Singh, M., \& Wamba, S. F. (2016). Enablers and barriers of flexible green supply chain management: A total interpretive structural modeling approach. Global Journal of Flexible Systems Management, 17(2), 171-188.

Singh, R. K., Kumar, R., \& Shankar, R. (2012). Supply chain management in SMEs: a case study. International Journal of Manufacturing Research, 7(2), 165-180.

Su, Q., Song, Y.T., Zhao, L., \& Ji-xiang D. (2008). The impact of supply chain relationship quality on cooperative strategy. Journal of Purchasing and Supply Management, 14(4), 263-272

Sáenz, M.S., Knoppen, D., \& Tachizawa E.M. (2018). Building manufacturing flexibility with strategic suppliers and contingent effect of product dynamism on customer satisfaction. Journal of Purchasing and Supply Management, 24(3), 238-246.

Seebacher, G., \& Winkler, H. (2015). A capability approach to evaluate supply chain flexibility. International Journal of Production Economics, 167,177-186.

Sushil, A. (2017). Modified ISM/TISM process with simultaneous transitivity checks for reducing direct pair comparisons. Global Journal of Flexible Systems Management, 18(4), 331-351.

Tan, K. C. (2002). Supply chain management: Practices, concerns, and performance issues. Journal of Supply Chain Management, 38, 42-53.

Tavani, S.N., Tavani, Z.N., Naudé, P., Oghazi, P., \& Zeynaloo, E. (2018). How collaborative innovation networks affect new product performance: Product innovation capability, process innovation capability, and absorptive capacity. Industrial Marketing Management, 73, 193-205.

Thakkar, J., Kanda, A., \& Deshmukh, S.G. (2010). Evaluation of buyer-supplier relationships using integrated mathematical approach of Interpretive Structural modelling (ISM) and graph theoretic matrix: The Case Study of Indian Automotive SMEs. Journal of Manufacturing Technology Management, 19(1), 92-124.

Thomas, A., Barton, R., \& Byard, P. (2008). Developing a Six Sigma maintenance model. Journal of Quality in Maintenance Engineering, 14, 262.

Tohidi, H., \& Jabbari, M.M. (2012). Product Innovation Performance in Organization. Procedia Technology, 1, 521-523.

Wang, C., Elizabeth A. Walker, \& Janice R. (2011a). Explaining the lack of strategic planning in SMEs: The importance of owner motivation. International Journal of Organisational Behaviour, 12 (1), 1-16.

Wang, L., Yeung, J. H. Y., \& Zhang, M. (2011b). The impact of trust and contract on innovation performance: The moderating role of environmental uncertainty. International Journal of Production Economics, 134(1), 114-122.

Wang, C. X., Qian, Z., \& Zhao, Y. (2018). Impact of manufacturer and retailer's market pricing power on customer satisfaction incentives in supply chains. International Journal of Production Economics, 205, 98-112.

Wright, R. (2013). Supply chain strategies of manufacturers in Romania. International Journal of Applied Management Science, 5(1), 80-99.

Warfield, J.W. (1974). Developing interconnected matrices in Structural modelling. IEEE Transcript on Systems, Men and Cybernetics, 4(1), 51-81.

Yang, M., \& Gabrielsson, P. (2017). Entrepreneurial marketing of international high-tech business-tobusiness new ventures: A decision-making process perspective. Industrial Marketing Management, 64, 147-160.

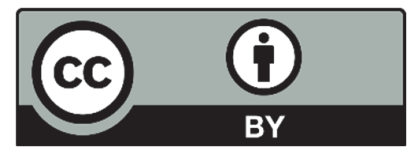

(C) 2020 by the authors; licensee Growing Science, Canada. This is an open access article distributed under the terms and conditions of the Creative Commons Attribution (CC-BY) license (http://creativecommons.org/licenses/by/4.0/). 